\title{
The effect of optically thin cirrus clouds on solar radiation in Camagüey, Cuba
}

\author{
B. Barja and J. C. Antuña \\ Meteorological Center of Camagüey, INSMET, Finlay Av., km 7 1/2 Camagüey, Cuba \\ Received: 14 January 2011 - Published in Atmos. Chem. Phys. Discuss.: 14 March 2011 \\ Revised: 6 June 2011 - Accepted: 11 July 2011 - Published: 24 August 2011
}

\begin{abstract}
The effect of optically thin cirrus clouds on solar radiation is analyzed by numerical simulation, using lidar measurements of cirrus conducted at Camagüey, Cuba. Sign and amplitude of the cirrus clouds effect on solar radiation is evaluated. There is a relation between the solar zenith angle and solar cirrus cloud radiative forcing (SCRF) present in the diurnal cycle of the SCRF. Maximums of SCRF out of noon located at the cirrus cloud base height are found for the thin and opaque cirrus clouds. The cirrus clouds optical depth (COD) threshold for having double SCRF maximum out of noon instead of a single one at noon was 0.083. In contrast, the heating rate shows a maximum at noon in the location of cirrus clouds maximum extinction values. Cirrus clouds have a cooling effect in the solar spectrum at the Top of the Atmosphere (TOA) and at the surface (SFC). The daily mean value of SCRF has an average value of $-9.1 \mathrm{~W} \mathrm{~m}^{-2}$ at TOA and $-5.6 \mathrm{~W} \mathrm{~m}^{-2}$ at SFC. The cirrus clouds also have a local heating effect on the atmospheric layer where they are located. Cirrus clouds have mean daily values of heating rates of $0.63 \mathrm{~K} \mathrm{day}^{-1}$ with a range between $0.35 \mathrm{~K} \mathrm{day}^{-1}$ and $1.24 \mathrm{~K} \mathrm{day}^{-1}$. The principal effect is in the near-infrared spectral band of the solar spectrum. There is a linear relation between SCRF and COD, with $-30 \mathrm{~W} \mathrm{~m}^{-2} \mathrm{COD}^{-1}$ and $-26 \mathrm{~W} \mathrm{~m}^{-2} \mathrm{COD}^{-1}$, values for the slopes of the fits at the TOA and SFC, respectively, in the broadband solar spectrum.
\end{abstract}

\section{Introduction}

Clouds play a key role in the climate system; the major clouds contribution to this system is their effects on the radiation. They modulate the radiation balance in the atmosphere. Particularly, cirrus clouds are widely recognized to play an important role in the radiation budget of the

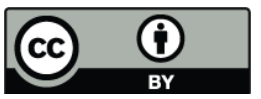

Correspondence to: B. Barja

(bbarja@cmw.insmet.cu)
Earth-atmosphere system and consequently in the climate (e.g. Schlimme et al., 2005; Futyan et al., 2005). Cirrus clouds have been identified as one of the sources of uncertainty in the study of Earth's radiation budget and climate (Lynch, 2002).

Cirrus clouds climatologies based on remote sensing measurements reveal high occurrence of cirrus clouds, both optically thick and thin cirrus clouds. Several studies have demonstrated that the global average frequency of cirrus cloud occurrence is near $27 \%$, reaching $45 \%$ in the Tropics (Stubenrauch et al., 2006). Nazaryan et al. (2008) shows cirrus clouds' frequency of occurrence of $70 \%$ in the tropics. The global average of cirrus clouds' occurrence frequency of $16.7 \%$ is shown by Sassen et al. (2008). The considerable coverage of cirrus clouds, their high altitude and their microphysical and radiative properties emphasizes them as a key factor controlling the vertical energy distribution in the upper troposphere and the total radiation budget of the Earth system.

The cirrus clouds radiative forcing $(\mathrm{CRF})$ is defined as the difference between irradiances calculated in the clear sky condition and the presence of cirrus clouds. CRF is well understood but not well quantified due to the incomplete knowledge of its properties. The CRF at the top of the atmosphere and surface have been studied by several authors (e.g. Ramaswamy and Ramanathan, 1989; Poetzsch-Heffter et al., 1995; Stubenrauch et al., 2006; Chen et al., 2000; Khvorostyanov y Sassen, 2002; Futyan et al., 2005; Dupont and Haeffelin, 2008). They show that CRF on the shortwave irradiances causes cooling in the atmosphere and its magnitude depends on cloud cover, optical thickness and the solar zenith angle.

The aim of this study is to quantify the CRF of cirrus clouds, measured with lidar in Camagüey, on the shortwave radiative irradiances. We simulate the cirrus clouds' effect on solar radiation using a state-of-the-art, one-dimensional radiative transfer code (Ramaswamy and Freidenreich, 1991; Freidenreich and Ramaswamy, 1999). The meteorological

Published by Copernicus Publications on behalf of the European Geosciences Union. 
variables' profiles introduced in the radiative transfer model were calculated for the local conditions at Camaguiey, Cuba. Vertical cloud structure was taken into account in solar flux density calculations. Thus, we can obtain reliable information about the behavior of solar radiation inside the cirrus clouds (Barja and Antuña, 2008). Cirrus optical depth (COD) profiles were obtained from lidar data on our site (Antuña and Barja, 2006). The lidar measurements were conducted with an aerosol-backscatter lidar, between 1993 and 1998, at the former Camagüey Lidar Station (currently Grupo de Óptica Atmosférica de Camagüey - GOAC). The lidar was located at the Camagüey Meteorological Center, Cuba, $21.4^{\circ} \mathrm{N}$ and $77.9^{\circ} \mathrm{W}$.

Shortwave broadband cirrus cloud radiative forcing and heating rates profiles were calculated. In Sect. 2 we discuss the data and radiative transfer code used in this study. Also, a definition and explanation about magnitudes used in the work is given. In Sect. 3 we discuss the results of the diurnal cycle of the solar cirrus cloud radiative forcing (SCRF) and heating rate. Three days are analyzed, representing the categories of optically thin cirrus clouds. A discussion about the daily mean values of upward and downward irradiances at TOA, SFC, cloud top and base is given in this section as well. Finally, in Sect. 4 we highlight the important conclusions resulting from this study.

\section{Data and methods}

The cirrus clouds' dataset consists of 132 individual lidar extinction profiles in 36 days of measurements from 1993 to 1998 (Antuña and Barja, 2006). Lidar measurements were made once per week at night around the year. The purpose of this lidar was to determine the backscattering profiles of stratospheric aerosols. Because of that constraint, the measurements were conducted in conditions of clear sky to the naked eye during night, when cirrus clouds were not apparent to the human eye. But, under those conditions when mainly optically thin cirrus clouds were present, in some cases we took the cirrus clouds' measurements. Thus, a total of 136 measurement days (stratospheric aerosols' measurement days plus cirrus measurement days) were conducted from 1993 to 1998. Cirrus cloud measurements were carried out in 36 days, with $28.3 \%$ of occurrence. So, the cirrus dataset is biased to thin cirrus cloud observations. Only a few percent of the measurements were thick cirrus clouds. The Lidar system used a doubled frequency Nd - YAG laser $\left(532 \mathrm{~nm}, 50 \mathrm{~Hz}, 300 \mathrm{~mJ}\right.$ pulse $\left.^{-1}\right)$ and the altitude resolution was $75 \mathrm{~m}$. The receiving telescope has $34 \mathrm{~cm}$ of diameter and the field of view is $3 \mathrm{mrad}$. The cirrus measurements averaged 1000 laser shots (Antuña and Barja, 2006).

Cirrus cloud extinction coefficient $(\alpha)$ profiles were calculated from the lidar backscattering coefficients' $(\beta)$ profile by the relation:

$\alpha=k \beta$, where $k$ is the extinction to backscatter ratio. The most suitable value of the extinction to backscattering ratio $(k)$, for our biased dataset, is $10 \mathrm{sr}$. A constant value of $k$ in the altitude is assumed in the calculations for simplicity. Thus, extinction coefficients profiles are 10 times backscattering coefficients' profiles (Antuña and Barja, 2006).

The evaluation of the radiative impact of the cirrus clouds measured in Camaguiey by lidar was carried out by the calculation of the SCRF. The SCRF is defined by the differences between simulated net solar radiative flux density obtained under clear and cloudy sky. To derive this quantity we used the expression:

$\mathrm{SCRF}=F_{\text {net }}^{\text {cloud }}-F_{\text {net }}^{\text {clear }}$,

$F_{\text {net }}$ is the simulated solar net flux density or irradiance, the difference between downward and upward flux densities; "cloud" means the presence of a cirrus cloud in the calculations. The superscript "clear" means clear sky conditions considering the same atmospheric and astronomical characteristics of the cirrus measurement day, but without the presence of the cirrus. SCFR values were calculated for the whole solar spectrum (broadband) as well as for the individual bands, ultraviolet $(0.174 \mu \mathrm{m}$ to $0.407 \mu \mathrm{m})$, visible $(0.407 \mu \mathrm{m}$ to $0.685 \mu \mathrm{m})$ and near-infrared $(0.685 \mu \mathrm{m}$ to $4.0 \mu \mathrm{m})$.

A state-of-the-art shortwave radiative transfer model (Ramaswamy and Freidenreich, 1991; Freidenreich and Ramaswamy, 1999) was used for the simulation. This code was developed in the Geophysical Fluid Dynamics Laboratory from the National Oceanic and Atmospheric Administration. The model includes particulate scattering and absorption, Rayleigh scattering, and gaseous absorption by $\mathrm{O}_{2}$, $\mathrm{O}_{3}, \mathrm{CO}_{2}$, and $\mathrm{H}_{2} \mathrm{O}$. The Code uses the vertical profiles of the gasses mass mixing ratio. The solar spectrum is divided into 25 pseudo-monochromatic bands between 0 and $57600 \mathrm{~cm}^{-1}$. Aerosol and cloud single-scattering properties are integrated into the 25 bands of radiative transfer model. A solar-flux weighted averaging scheme is used to integrate these properties. Reflection and transmission for homogeneous layers is calculated with the $\delta$-Eddington method. Vertical profiles of flux densities and heating rates are obtained by the "doubling-adding" technique. Freidenreich and Ramaswamy (1999) compare results from the code with lineby-line plus doubling-adding reference computations without cloud or aerosol. These comparisons give errors of $10 \%$ for heating rates, and $2 \%$ for atmospheric absorbed flux density.

The code was adapted to the local conditions substituting the prescribed temperature and water vapor mixing ratio profiles by the ones determined for Camagüey (Barja and Antuña, 2008). The temperature and water vapor mixing ratio vertical profiles for Camagüey were acquired from the mean aerological sounding in the site with the dataset from 1981 to 1988 . Values of the pressure, temperature and water 
vapor mixing ratio at the surface were obtained from the Camagüey Meteorological Surface Station reports dataset from 1988 to 2001. The surface albedo average value of 0.22 was used in calculations fixed for the different spectral bands, obtained from actinometric broadband measurements at the site. The vertical profile of $\mathrm{O}_{3}$ mass mixing ratio was the midlatitude summer (MLS) atmosphere from McClatchey (1972).

The solar radiative properties of cirrus clouds in the code calculations were represented by Fu's parameterization (Fu, 1996). Fu's parameterization uses ice crystal generalized effective size $\left(D_{\mathrm{ge}}\right)$ as a representation of the crystal size. This parameterization combine the extinction coefficient with $D_{\text {ge }}$ and ice water content (IWC) assuming that hexagonal ice crystals are randomly oriented in space, by the relation:

$\alpha=\frac{4(3)^{1 / 2}}{3 \rho_{i}} \frac{\mathrm{IWC}}{D_{\mathrm{ge}}}$,

where $\rho_{i}$, is the ice density. Fu (1996) obtained a set of coefficients in 25 bands of the solar spectrum to parameterize the cirrus clouds' single scattering properties (extinction coefficient, single scattering albedo and asymmetry factor). In the code, two methods could be used to obtain the ice particle coalbedo, referred to as thin-averaging and thick-averaging techniques. The first one defines the coalbedo as the solar weighted mean value over the spectral interval band. That method was selected because of the small geometrical depth of our cirrus clouds dataset.

To consider cirrus structure in the simulation and analyze the behavior of the solar radiative transfer inside the cirrus clouds, several actions were conducted. The profiles of the COD values at the coincident altitudes of the cirrus clouds and the bins of the radiative transfer code were calculated from the cirrus lidar extinction profiles. Also the profiles of the ice crystal generalized effective size $\left(D_{\mathrm{ge}}\right)$ for the cirrus cloud particles at those bins were calculated. For such a goal, the daily mean temperature profiles from the reanalysis data (NCEP, 2005) were calculated from the temperature profiles of the two most near grid points south and north of the lidar location (Barja and Antuña, 2008).

To consider cirrus structure in the simulation and analyze the behavior of the solar radiative transfer inside the cirrus clouds, several actions were conducted. The profiles of the COD values at the coincident altitudes of the cirrus clouds and the bins of the radiative transfer code were calculated from the cirrus lidar extinction profiles. The resolution of the lidar measurements is smaller than the resolution of the code, at the altitude of the cirrus clouds. Thus, one layer of the code includes some lidar layers. The measurements' vertical resolution was adjusted to the layers used in the code by the following relation:

$\tau_{\mathrm{cl}}=\sum_{n} \alpha_{n} \Delta z$ where $\tau_{\mathrm{cl}}$ is the COD in the code layer, $\alpha_{n}$ the extinction coefficients in the layers of lidar profile, $n$ is the number of lidar layers included in the code layer, $\Delta z$ is the geometrical depth of the lidar layer, $75 \mathrm{~m}$ (Barja and Antuña, 2008). Also the ice crystal generalized effective size profiles $\left(D_{\text {ge }}\right)$ for the cirrus clouds particles at code bins were calculated. For a such goal, daily mean temperature profiles were calculated from reanalysis data (NCEP, 2005) at the two most near grid points south and north of the lidar location (Barja and Antuña, 2008).

The downward and upward irradiances, heating rates, and cloud forcing profiles were calculated for each hour of the cirrus measurements' day. It was considered that the measured cirrus clouds were present at all hours of the day, with the same characteristics. In the night hours, solar irradiance zero values were considered. Thus diurnal cycles of the SCRF and the heating rate for 132 profiles were derived. Three cases of diurnal cycle of cirrus clouds were selected for discussion, representing different types of optically thin cirrus clouds following the classification of Sassen and Cho (1992). The frequency of occurrence of three types of thin cirrus clouds in the 132 cases is $8 \%, 67 \%$ and $25 \%$ for opaque, thin and subvisible cirrus clouds, respectively (Antuña and Barja, 2006). Daily mean values of upward and downward irradiance at the TOA, SFC, cloud base and top were calculated for the $24 \mathrm{~h}$ of the day with the 132 lidar profiles. Also, the mean values of SCRF at TOA and SFC were calculated for each 132 day simulations, three categories of cirrus clouds, and all the 132 cirrus cases.

\section{Results and discussion}

\subsection{Diurnal cycles of the heating rate and SCRF}

Figure 1 is a composite of selected cases representing the opaque, thin and subvisible cirrus clouds following the optically thin cirrus cloud classification of Sassen and Cho (1992). For each case the cirrus extinction profile and the diurnal cycles of the heating rate and broadband SCRF are shown. On the top panel of Fig. 1, the opaque cirrus case is depicted. This is the thickest cirrus cloud measured in $\mathrm{Ca}-$ magüey with lidar. This cirrus was measured on 11 August 1998, 04:46 UTC having an optical depth and mean generalized effective size values of 2.74 and $16.9 \mu \mathrm{m}$, respectively. The cirrus was located between the altitudes of $9.39 \mathrm{~km}$ and $15.24 \mathrm{~km}$, corresponding to pressures between $320 \mathrm{hPa}$ and $120 \mathrm{hPa}$. The diurnal cycle of the heating rate, Fig. 1b, shows maximum values of the heating rate at the location of cirrus clouds' maximum extinction values, Fig. 1a. The maximum values for the heating rate in the day, $5.59 \mathrm{~K} \mathrm{day}^{-1}$, occurred at noon. These positive values denote a radiative heating of the atmosphere. Although for an atmosphere almost free of clouds the scattering of solar radiation is the predominant process in radiative transfer, at the levels where cirrus 
11 August 1998, 4:46 UTC
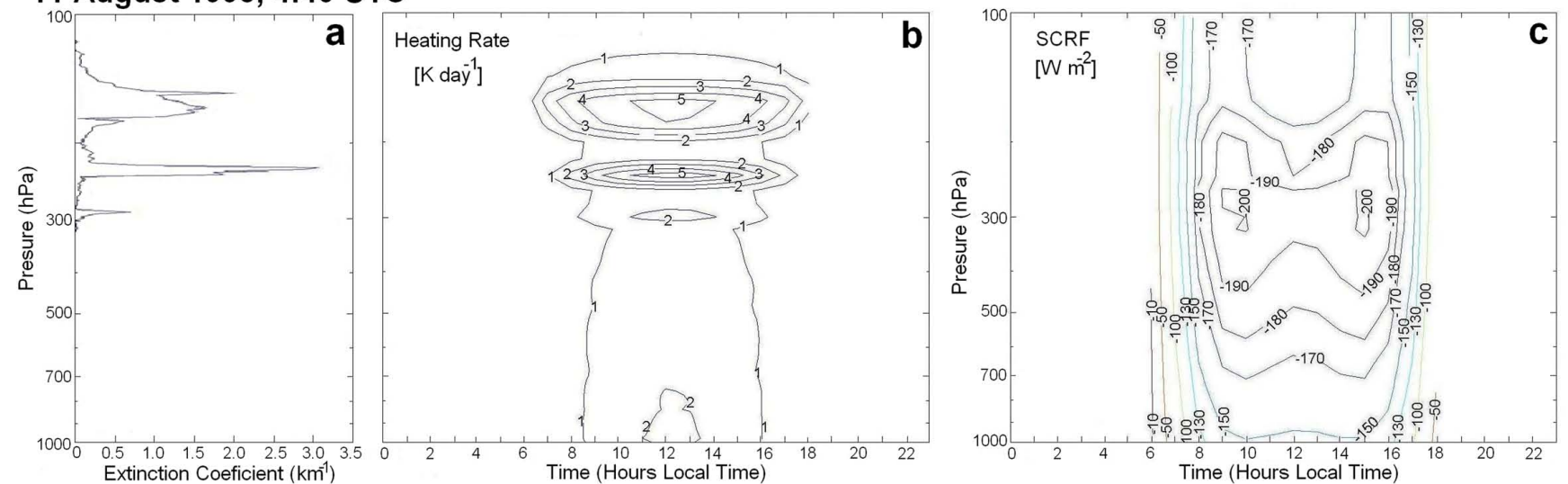

25 August 1996, 8:15 UTC
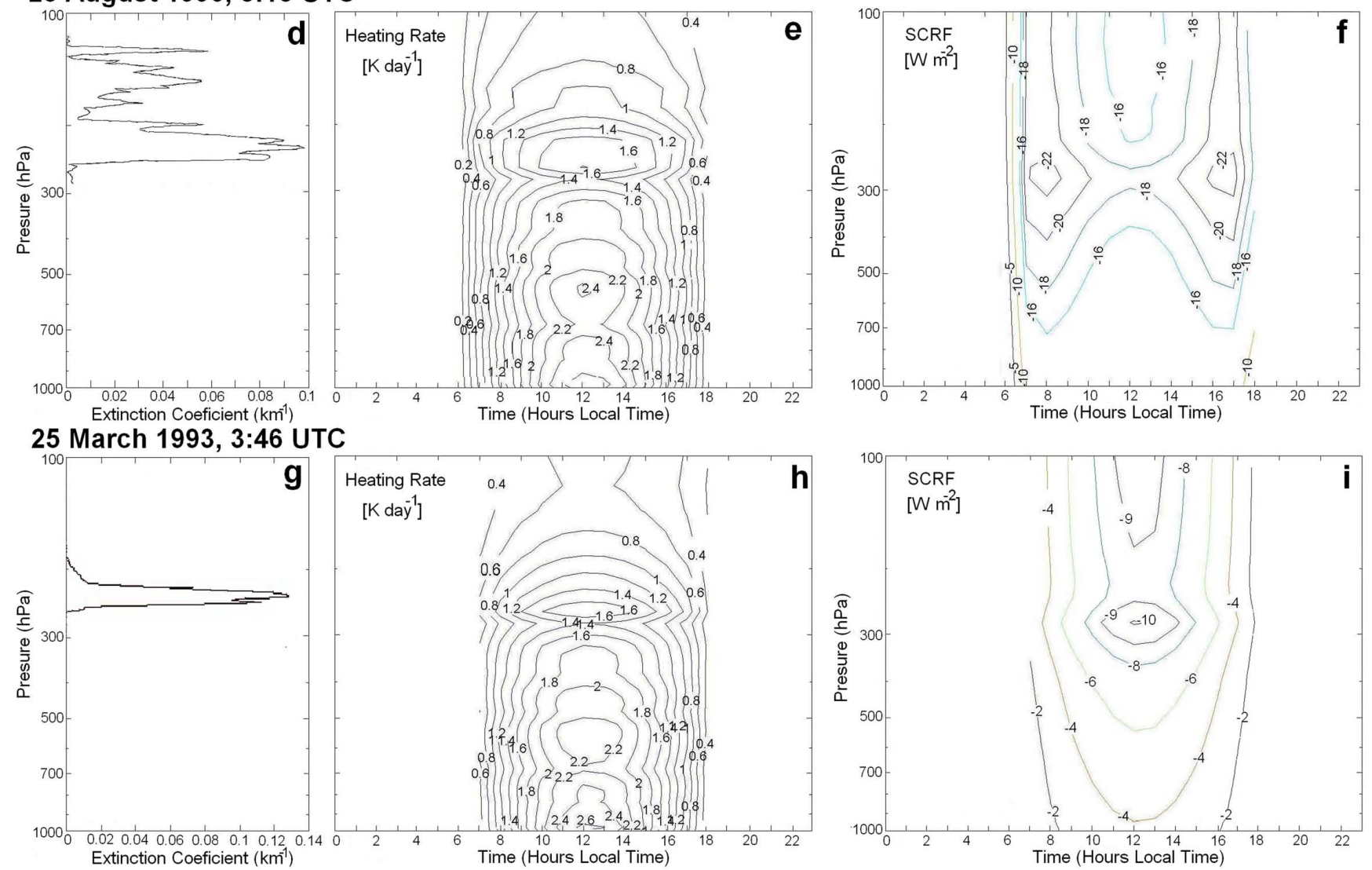

Fig. 1. Examples of cirrus clouds cases: extinction coefficient profiles, diurnal cycle of heating rate and SCRF. Top panel: Opaque cirrus cloud; medium panel: Thin cirrus cloud; bottom panel: Subvisible cirrus cloud.

clouds are present, the solar absorption due cirrus clouds becomes an important process, enough to cause this heating (Ramaswamy and Ramanathan, 1989).

Figure 1c shows that during the whole diurnal cycle, the broadband SCRF has negative values, indicating the effect of the cirrus clouds in different altitudes of the atmosphere. In the presence of cirrus clouds, more solar radiation escapes in the top of the atmosphere and less solar radiation reaches the terrestrial surface. Two maximum values of the broad- band SCRF, considering absolute values, -200.6 $\mathrm{W} \mathrm{m}^{-2}$ and $-201.7 \mathrm{~W} \mathrm{~m}^{-2}$ are clearly seen at 9 and 15 local time (LT: UTC - 05:00), respectively, in Fig. 1c. At these times the relative solar zenith angle was near to $39^{\circ}$. The presence of both maximums in the broadband SCRF is the result of the combination of the atmospheric optical path with the cirrus cloud incidence and the solar radiation available at these times, discussed below in detail by their importance. In altitude the maximum values of the broadband SCRF are 
reached near the base height of the cirrus clouds, at $280 \mathrm{hPa}$.

The medium panel in Fig. 1 illustrates the thin cirrus case. It was measured on 25 August 1996, 08:15 UTC with an optical depth and mean generalized effective size values of 0.16 and $18.7 \mu \mathrm{m}$, respectively. The cirrus clouds' altitude is between $10.59 \mathrm{~km}$ and $15.16 \mathrm{~km}$, corresponding to pressure values between $280 \mathrm{hPa}$ and $120 \mathrm{hPa}$. Its structure is shown in the Fig. 1d. Note that the maximum value for the extinction coefficient in this case is $0.098 \mathrm{~km}^{-1}$. This value is one order of magnitude less than $3.06 \mathrm{~km}^{-1}$, the maximum value of extinction coefficient of the opaque cirrus case. The secondary peak of the thin cirrus cloud has a maximum extinction coefficient value of $0.06 \mathrm{~km}^{-1}$. It is two orders less than $2.0 \mathrm{~km}^{-1}$, the maximum value of the extinction coefficient secondary peak in the opaque cirrus cloud. The structure of these two cases is similar; they have one principal peak and one secondary peak in the extinction coefficient profile. The difference between these two profiles is in the order of magnitude of the extinction coefficient values.

As in the opaque cirrus case, the heating rate diurnal cycle for the thin cirrus case has a maximum value of $1.8 \mathrm{~K} \mathrm{day}^{-1}$ in the location of cirrus, at noon (Fig. 1e). This maximum occurs only at the same location of the principal cirrus cloud peak. The secondary peak in the cirrus cloud structure, with lower values of the extinction coefficient, does not produce high values in the heating rate. Also there are maximum values in the lower troposphere (values of pressure higher than $300 \mathrm{hPa}$ ). These maximums correspond to the absorption effect of the water vapor taken into account in the radiative transfer code calculations. In the troposphere, for pressure below $300 \mathrm{hPa}$ we have a water vapor mixing ratio range from 0.0014 at $300 \mathrm{hPa}$ to 0.0154 at near of SFC.

The diurnal cycle of the broadband SCRF for the thin cirrus case is shown in Fig. 1f. The sign of the values is negatively indicative of the radiative cooling of the atmosphere. This negative sign denotes that more radiation escapes the top of the atmosphere in the presence of cirrus clouds. However, the broadband SCRF values have less magnitude because of the smaller COD. Like the opaque cirrus case, there are two SCRF maximums in the day, at 8 and 17:00 LT, both with a value of $-22.8 \mathrm{~W} \mathrm{~m}^{-2}$, considering absolute values. At these times, the relative solar zenith angle was near to $61^{\circ}$. Also, like the opaque case, the maximum of SCRF is located near the cirrus cloud base height, at $260 \mathrm{hPa}$. Analogous to the opaque cirrus case, the diurnal behavior of the SCRF shows the result of the combination of the atmospheric optical path with the cirrus cloud incidence and the solar radiation available at these times, discussed below in detail by their importance.

The bottom panel of Fig. 1 shows the subvisual cirrus case. It was measured on 25 March 1993, 03:46 UTC with an optical depth and mean generalized effective size values of 0.004 and $15.7 \mu \mathrm{m}$. The cirrus cloud was located between $10.51 \mathrm{~km}$ and $12.24 \mathrm{~km}$ in altitude, equivalent to pressure values between $280 \mathrm{hPa}$ and $200 \mathrm{hPa}$. The subvisible cirrus cloud structure is shown in Fig. 1g. The extinction coefficient profile has only one peak, with a maximum value of $0.14 \mathrm{~km}^{-1}$. This peak has similar characteristics to the principal peak in the thin cirrus case. Like the thin cirrus case, the diurnal cycle of heating rate of subvisible cirrus cloud has a maximum value of $1.8 \mathrm{~K} \mathrm{day}^{-1}$, in the location of the cirrus, at noon (Fig. 1h). Also, there are maximums in the lower troposphere produced by the water vapor absorption. The broadband SCRF diurnal cycle for the subvisible cirrus cloud case is shown in Fig. 1i. It shows broadband SCRF negative values similar to the other cases. The magnitude of the SCRF in the subvisible cirrus case is, however, smaller than the other cases analyzed previously. Consistent with the theory, Fig. 1 shows that the values of the broadband SCRF vary depending on the cirrus cloud optical thickness. Greater values of the broadband SCRF are registered for opaque clouds and smaller for subvisible clouds. In contrast with the two cirrus cases analyzed above, for the subvisible cirrus case there is only one maximum of the broadband SCRF. That maximum occurs at noon, located in the base height at $280 \mathrm{hPa}$, with a value of $-10.1 \mathrm{~W} \mathrm{~m}^{-2}$, considering absolute values.

In general the calculations show that the heating rate has positive values during the day for the three cases studied. The maximum value of the heating rate is obtained in the case of the cirrus clouds with the higher COD in our data. The maximum values of the heating rate in the day are reached at noon and in the location of the cirrus clouds, following its vertical structure.

The broadband SCRF has negative values during the course of the day in all cases. The maximum values are located near the base of the cirrus clouds in all cases. For the subvisible cirrus, the maximum broadband SCRF is reached at noon. But for the opaque and thin cirrus cases, there are two maximums not at noon but in the middle morning and afternoon. To the authors' knowledge, that last feature has not been reported in the literature. An explanation for such a feature is the different magnitudes of the contribution to the solar irradiance increase during the day, both by the cirrus cloud atmospheric optical path and the elevation of the sun. In the middle morning and middle afternoon hours the optical path is greater than at noon. For this reason, there is more dispersion and absorption when the solar radiation traverses the atmosphere through the cirrus cloud with same characteristics considered present all day. At the first and last hours in the day, the cirrus optical path has its highest values and the solar radiation irradiances the lowest. At noon, the cirrus optical path has its lowest values and the solar radiation has the highest values. As the broadband SCRF is the difference between irradiances under clear and cloudy conditions, then the SCRF reaches its maximum values at the middle morning and afternoon, in the cases of opaque and thin cirrus clouds. Both the cirrus optical path and the sun elevation in the course of the day produce an increase of the net solar radiation both for clear and cloudy sky, but at different rates between the clear and cloudy sky. 


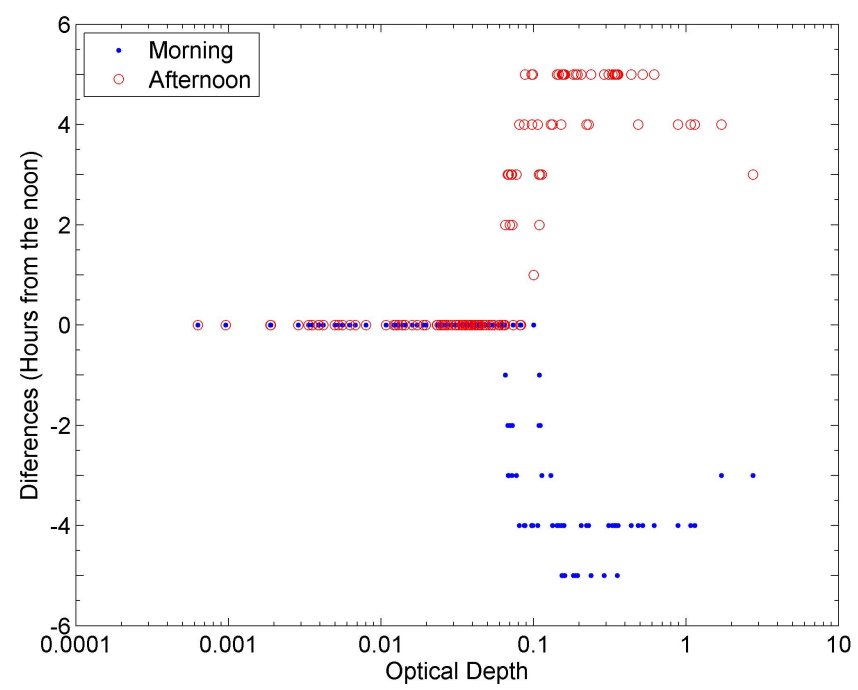

Fig. 2. Plot of the differences between hour of maximum SCRF and noontime (12:00 LT) versus optical depth for the clouds measured with lidar in Camagüey. Threshold value is 0.083 for the occurrence of the maximum out of noon.

Based on the fact that the double maximum was present in the thin and opaque cirrus clouds cases but not in the subvisible, we determined the threshold for such a feature. We use the calculation of SCRF with each 132 cirrus profiles, with characteristics for each cirrus case and mean profiles of the atmosphere. The COD threshold for having double broadband SCRF maximum out of noon instead of a single one at noon was 0.083 . Figure 2 shows the differences between noon (12:00 LT) and the hour of maximum SCRF in the morning and afternoon depending optical depth. Positive and negative difference values denote the maximum occurring in the afternoon and in the morning, respectively, and zero values indicate the maximum at noon. The maximum values of SRCF out of noon begin to occur with COD value of 0.065 . Thus, the subvisible cirrus clouds (optical depth below 0.03 ) produce the maximum value of SCRF at noon. The opaque clouds (optical depth above 0.3 ) produce the maximum value of SCRF out of noontime. Thin cirrus clouds (optical depth between 0.03 and 0.3 ) can produce the maximum values both at noon and out of noon.

Simulation of the diurnal cycle of the cirrus clouds heating rate and SCRF is shown by Khvorostyanov and Sassen (2002). The authors used a mesoscale 2-D cloud model with explicit microphysics and radiation, also simulated dynamics and chemicals in the atmosphere. They performed calculations to three cases of cirrus clouds types, two in the thin cirrus clouds category and one as subvisible cirrus cloud. Their results show the maximum of the SCRF at noon. In these three cases the shortwave heating rate and cloud forcing have positive and negative values respectively. The maximum values of the cloud forcing are reached in the location of cirrus clouds at noon. The magnitude of the values of the
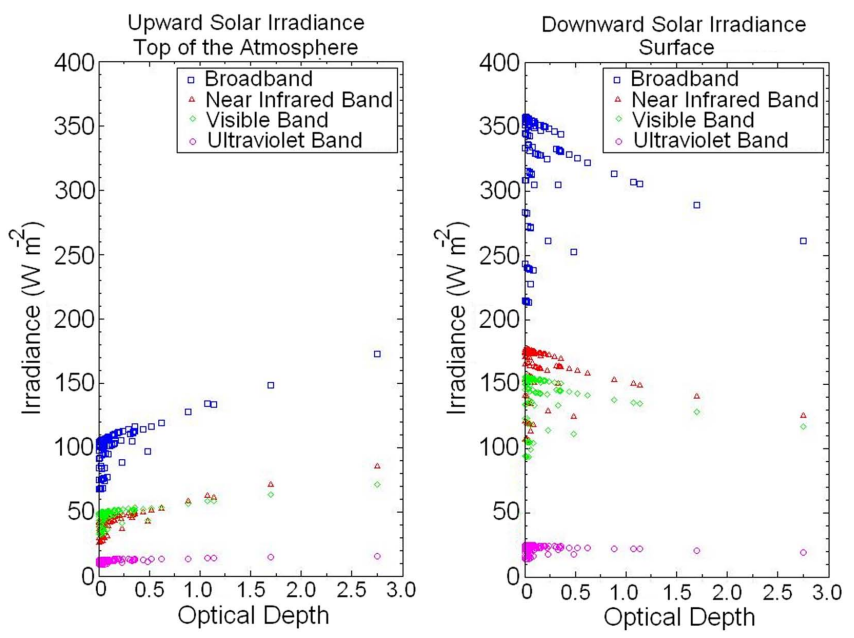

Fig. 3. Daily mean solar irradiance in presence of cirrus clouds. Upward irradiance at TOA and downward irradiance at SFC, for the solar radiation broadband and spectral bands, versus cirrus optical depth for the all cirrus measured with lidar in Camagüey.

diurnal cycle for the heating rate and SCRF obtained in the present work are in the same order of magnitude of the results reported in the above paper. Our calculations were run with a shortwave radiative transfer code (Freidenreich and Ramaswamy, 1999), which differs from the mesoscale 2-D model used by Khvorostyanov and Sassen (2002). Despite the difference between the models, it is possible to make a qualitative comparison.

\subsection{Daily mean solar cirrus radiative forcing}

The plots of daily mean upward flux densities at the top of the atmosphere (TOA) and the daily mean downward flux densities at the surface (SFC) versus COD are presented in Fig. 3. These irradiances were calculated both for the broadband and for the different spectral bands of the solar radiation (near- infrared, visible, ultraviolet). The broadband solar upward irradiance in the TOA and downward irradiance in the SFC rise and drop respectively, with the increase of the COD. Also these tendencies occur for the three spectral bands of the solar radiation. These responses of the irradiances to the rise in the optical depth are produced by the increase of the reflection and dispersion events in the interaction of the solar radiation with the ice crystal in the cloud. A large number of ice crystals leads to an increase of optical depth. There are also few absorption processes.

For the broadband, the values of the upward irradiances in the TOA range between $166.6 \mathrm{~W} \mathrm{~m}^{-2}$ and $60.2 \mathrm{~W} \mathrm{~m}^{-2}$, with a mean value of $91.1 \mathrm{~W} \mathrm{~m}^{-2}$. The values of the downward irradiances in the surface range between $212.8 \mathrm{~W} \mathrm{~m}^{-2}$ and $356.2 \mathrm{~W} \mathrm{~m}^{-2}$, with a mean value of $322.2 \mathrm{~W} \mathrm{~m}^{-2}$. The flux densities in the different spectral bands have a similar behavior, but with lower magnitude of the values. The mean 
Table 1. Average, maximum and minimum values of upward at TOA and cloud top and downward irradiances at SFC and cloud base. In the broadband, near- infrared, visible and ultraviolet bands.

\begin{tabular}{lccccccc}
\hline & \multicolumn{7}{c}{ Irradiance $\left(\mathrm{W} \mathrm{m}^{-2}\right)$} \\
\cline { 2 - 7 } & \multicolumn{2}{c}{ Upward Irradiance TOA } & \multicolumn{2}{c}{ Downward Irradiance SFC } & Solar Irradiance \\
& Mean & Max & Min & Mean & Max & Min & at TOA Percent \\
\hline Solar Broadband & 91.1 & 166.6 & 60.2 & 322.2 & 356.2 & 212.8 & 100 \\
Near Infrared & 37.5 & 82.7 & 22.8 & 160.1 & 177.2 & 106.2 & 55.2 \\
Visible & 42.6 & 68.6 & 29.1 & 140.3 & 154.8 & 92.8 & 36.4 \\
Ultraviolet & 11.4 & 15.2 & 8.23 & 21.3 & 24.1 & 13.7 & 8.4 \\
\hline & Upward Irradiance cloud top & Downward Irradiance cloud base & Solar Irradiance \\
& Mean & Max & Min & Mean & Max & Min & at TOA Percent \\
\hline Solar Broadband & 89.6 & 167.2 & 57.7 & 399.5 & 448.6 & 271.3 & 100 \\
Near Infrared & 37.0 & 83.0 & 22.7 & 222.8 & 252.2 & 152.7 & 55.2 \\
Visible & 41.8 & 69.1 & 27.6 & 149.7 & 165.9 & 100.9 & 36.4 \\
Ultraviolet & 10.8 & 15.1 & 7.2 & 26.9 & 30.6 & 17.8 & 8.4 \\
\hline
\end{tabular}
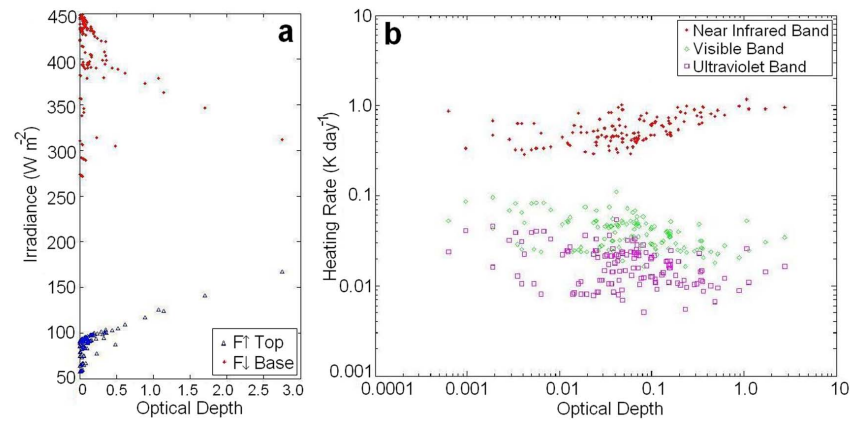

Fig. 4. (a) Broadband irradiances versus optical depths. Upward irradiance at the cloud top ( $F \uparrow$ Top) and downward irradiance at the cloud base ( $F \downarrow$ Base), for all studied clouds. (b) Daily Mean Heating rates for all studied cirrus clouds at each spectral solar band versus their optical depth.

values of the upward irradiance in TOA (downward irradiance in SFC) are $37.5 \mathrm{~W} \mathrm{~m}^{-2}\left(160.1 \mathrm{~W} \mathrm{~m}^{-2}\right), 42.6 \mathrm{~W} \mathrm{~m}^{-2}$ $\left(140.3 \mathrm{~W} \mathrm{~m}^{-2}\right)$, and $11.4 \mathrm{~W} \mathrm{~m}^{-2}\left(21.3 \mathrm{~W} \mathrm{~m}^{-2}\right)$, for the nearinfrared, visible, and ultraviolet spectral bands, respectively. The major contribution to the broadband solar radiation is in the spectral bands of near-infrared and visible, in correspondence with the spectral components of the solar radiation.

Figure 4a shows the broadband upward and downward flux densities at the heights of the cirrus clouds' tops and bases. All the cases of the cirrus clouds are analyzed. The values of broadband upward irradiance in the cirrus top height range between $57.7 \mathrm{~W} \mathrm{~m}^{-2}$ and $167.2 \mathrm{~W} \mathrm{~m}^{-2}$, with a mean value of $89.6 \mathrm{~W} \mathrm{~m}^{-2}$. These values are similar to the broadband upward irradiance at TOA (Fig. 3). This shows that the upward irradiances in the TOA are influenced directly by the albedo effect caused by cirrus clouds. In contrast, the downward irradiances in the base height range between $271.3 \mathrm{~W} \mathrm{~m}^{-2}$ and
448.6 $\mathrm{W} \mathrm{m}^{-2}$ with mean value of $399.5 \mathrm{~W} \mathrm{~m}^{-2}$. These flux densities are higher than the downward irradiance in SFC. Table 1 shows the values of upward irradiance at TOA and cloud top, also the downward irradiance at cloud base and SFC. These differences between irradiances at cloud base and surface support the explanation of the key role played by the water vapor and other trace gases in the lower troposphere radiative transfer processes. Solar radiation in the red and near-infrared regions of the spectrum is absorbed to some extent by carbon dioxide, ozone, and water present in the atmosphere in the form of vapor. Scattering takes place in the lower atmosphere caused by dust, fog, and clouds with particle sizes more than ten times the wavelength of the components of solar radiation in the same magnitude in all wavelengths of the solar spectrum. Also, atmospheric selective scattering is inversely proportional to the fourth power of the wavelength of radiation and therefore, the most severely scattered radiation is that which falls in the ultraviolet, violet, and blue bands of the spectrum. Thus, both the absorption and scattering in the lower troposphere reduce the solar radiation that finally reaches the surface. That is in contrast with the behavior in the upper troposphere, where the water vapor and other gases have a lower concentration. At this altitude, cirrus clouds are an important contributor to the atmospheric solar radiation transfer. The flux densities have a trend with respect to optical depth similar to TOA and SFC cases. As the COD increases, the irradiance in the cirrus top increase and the fluxes in the cirrus base decrease.

The mean value of the heating rate for the layers where the cirrus is located was calculated for each hour in the day. Using these values, a daily average of the heating rate was obtained for each spectral band of the solar radiation. The relation between these values and the optical depth are shown in Fig. 4b. In general, when the optical depth increases, the daily mean heating rates increase, too, in the near-infrared 
band. The daily mean heating rates' values range between $0.35 \mathrm{~K} \mathrm{day}^{-1}$ and $1.24 \mathrm{~K} \mathrm{day}^{-1}$, and its average value is $0.63 \mathrm{~K} \mathrm{day}^{-1}$. Also, it is shown in Fig. $4 \mathrm{~b}$ that the principal contribution to the heating rates in the solar radiation is in the near-infrared spectral band with values one order of magnitude higher than the values of the others spectral bands. This main effect of the cirrus clouds over the near-infrared spectral band of the solar radiation has been reported in the literature (e.g., Ramaswamy and Ramanathan, 1989).

The positive slope of $0.31 \mathrm{~K} \mathrm{day}^{-1} \mathrm{COD}^{-1}$ in the near-infrared spectral bands points differ from the negative slope with values of $-0.01 \mathrm{~K} \mathrm{day}^{-1} \mathrm{COD}^{-1}$ and $-0.005 \mathrm{~K} \mathrm{day}^{-1} \mathrm{COD}^{-1}$ in the visible and ultraviolet bands, respectively. In order to examine this aspect, the statistical significance (99\%) of the slope was tested using the Tstudent test with the hypothesis that the slope is zero; that is no dependence of the heating rate on COD. The results show that there is dependence of the heating rate with COD in the near-infrared band. On the other hand, there is no dependence in the visible and ultraviolet spectral bands.

Ramaswamy and Ramanathan (1989) reported an increment of $1.1 \mathrm{~K} \mathrm{day}^{-1}$ in the heating rate, when considering the presence of cirrus clouds. The cirrus clouds used in the simulation by those authors have an ice crystal distribution represented by spheres, with an optical depth of 1.5. This value is in the range of the heating rates reported in our cases.

Figure 5 shows the relation between daily mean SCRF values and COD, for the solar broadband radiation as well as their different spectral bands both at TOA and SFC. There is a negative linear relation between SCRF and optical depth both at TOA and SFC. The negative values of SCRF indicate that cirrus clouds cool radiatively the TOA and SFC. The cirrus cloud presence in the atmosphere determines that the solar radiation upwelling irradiance in the TOA increases and the solar radiation downwelling irradiance in the SFC decreases. These effects will increase as the COD increases. There is a negative linear relation between SCRF and the optical depth in broadband solar radiation, both at TOA and SFC, with $-30 \mathrm{~W} \mathrm{~m}^{-2} \mathrm{COD}^{-1}$ and $-26 \mathrm{~W} \mathrm{~m}^{-2} \mathrm{COD}^{-1}$, values for the slopes of the fits with a correlation factor of 0.98 . Also Fig. 5 shows that the main contribution to this effect is in the near-infrared band of the solar radiation. The average contribution to the broadband SCRF at TOA (SFC) is $85 \%(75 \%)$ in the near-infrared band, $13 \%(22 \%)$ in the visible band and $2 \%(3 \%)$ in the ultraviolet band. This main contribution of the near-infrared band in the solar interaction with the cirrus clouds is reported by Ramaswamy and Ramanathan (1989). The daily values of SCRF in the TOA (SFC), for the broadband solar radiation, range from $-2.8 \mathrm{~W} \mathrm{~m}^{-2}$ $\left(-0.9 \mathrm{~W} \mathrm{~m}^{-2}\right)$ to $-81.5 \mathrm{~W} \mathrm{~m}^{-2}\left(-68.1 \mathrm{~W} \mathrm{~m}^{-2}\right)$, with mean value of $-9.1 \mathrm{~W} \mathrm{~m}^{-2}\left(-5.6 \mathrm{~W} \mathrm{~m}^{-2}\right)$.

Table 2 compiles the mean, minimum and maximum values of the SCRF at TOA and SFC for the different cirrus cloud types, following the classification of Sassen and Cho
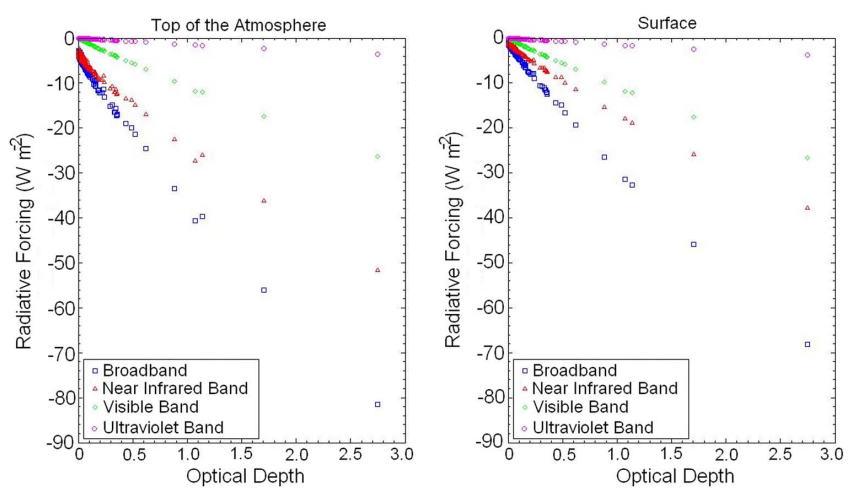

Fig. 5. Relation between daily mean value of SCRF, both for the broadband and the spectral bands of solar radiation, and the cirrus optical depths, for all dataset.

Table 2. Average, minimum and maximum values of the SCRF for the different cirrus types on the TOA y SFC.

\begin{tabular}{lcccccc}
\hline SCRF & \multicolumn{2}{c}{ Opaque } & \multicolumn{2}{c}{ Thin } & \multicolumn{2}{c}{ Subvisible } \\
$\left(\mathrm{W} \mathrm{m}^{-2}\right)$ & TOA & SFC & TOA & SFC & TOA & SFC \\
\hline Mean & -28.2 & -21.9 & -7.6 & -4.3 & -4.2 & -1.7 \\
Minimum & -14.8 & -10.7 & -4.2 & -2.0 & -2.8 & -0.9 \\
Maximum & -81.5 & -68.1 & -15.2 & -10.6 & -7.6 & -4.0 \\
\hline
\end{tabular}

(1992). The relation between SCRF and COD is clear. For low optical depth (subvisible cirrus), there is low SCRF and for high optical depth (opaque cirrus) there is a high value of SCRF. Only $14 \%$ of the cirrus clouds have SCRF values higher than $15 \mathrm{~W} \mathrm{~m}^{-2}$. Our dataset is representative of the thin and subvisible cirrus clouds. Also, note in the Table 2 that the three cirrus types have a higher effect at TOA than at SFC.

The negative sign and the linear relation with the optical depth of the SCRF are reported in the literature. Jensen et al. (1994), report a negative sign of SCRF in the broadband solar radiation, with values lower than $-80 \mathrm{~W} \mathrm{~m}^{-2}$, for optical depth below 5. The authors show a linear relation between SCRF and lower values of the optical depth. The authors made theoretical calculations with an ice crystal effective radius of $15 \mu \mathrm{m}$, and a cloud altitude between $13 \mathrm{~km}$ and $15 \mathrm{~km}$, in the case of tropical cirrus clouds.

\section{Conclusions}

Lidar surface-based measurements collected in Camagüey, Cuba, were used in this study to determine the magnitude and nature of the effect of the cirrus cloud on solar radiation. In 132 single cirrus cases, lidar measurements were used in the radiative transfer simulations. Using these simulations' results, we derived the diurnal cycle of the solar irradiances, 
heating rates, and SCRF verticals' distributions in the atmosphere. Also, the daily mean values of the SCRF and heating rates were calculated.

Cirrus clouds have a cooling effect at TOA and SFC. More solar radiation escapes from the planet and less solar radiation reaches the surface in the presence of cirrus clouds. The magnitude of this effect depends on the COD and the solar elevation angle. There is a negative linear relation between SCRF and the optical depth, both at TOA and SFC, with $-30 \mathrm{~W} \mathrm{~m}^{-2} \mathrm{COD}^{-1}$ and $-26 \mathrm{~W} \mathrm{~m}^{-2} \mathrm{COD}^{-1}$, values for the slopes of the fits. The daily mean value of SCRF at TOA has an average value of $-9.1 \mathrm{~W} \mathrm{~m}^{-2}$ while at SFC it is $-5.6 \mathrm{~W} \mathrm{~m}^{-2}$. The upward and downward flux densities at TOA have a mean value of $91.1 \mathrm{~W} \mathrm{~m}^{-2}$ and $322.2 \mathrm{~W} \mathrm{~m}^{-2}$, respectively. Solar radiation flux densities have a similar behavior in the three spectral bands in relation to the optical depth. The principal contribution is in the near-infrared spectral band. Cirrus clouds have mean daily values of the heating rates $0.63 \mathrm{~K} \mathrm{day}^{-1}$, ranging from $0.35 \mathrm{~K} \mathrm{day}^{-1}$ to $1.24 \mathrm{~K} \mathrm{day}^{-1}$.

The diurnal cycles of the SCRF and heating rates in the solar radiation broadband have been calculated. A feature not reported before in the SCRF diurnal cycle has been found; for the cirrus classified as thin and opaque, the maximum of the SCRF is out of noontime. The threshold value of COD for the appearance of that feature in our dataset is 0.083 . An explanation for this is the simultaneous variations of the relation of SCRF with COD and solar elevation angle.

Acknowledgements. This work was supported by the Cuban Program of Climate Change and Environment under contract No. 01301204.

The authors wish to express their deep gratitude to V. Ramaswamy and S. M. Freidenreich for providing the radiative code and their advice during the code implementation for PC and results analyses.

NCEP Reanalysis data was provided by the NOAA-CIRES Climate Diagnostics Center, Boulder, Colorado, USA, from their Web site at http://www.cdc.noaa.gov/. We are grateful to all reviewers and editor for their significant contributions. We also thank the staff of the Copernicus Publications for their professional and friendly collaboration.

Edited by: M. Krämer

\section{References}

Antuña, J. C. and Barja, B.: Propiedades Ópticas de Nubes Cirros Medidas con Lidar en Camagüey, Cuba, Óptica Pura y Aplicada, 39, 11-16, 2006.

Barja, B. and Antuña, J. C.: Numerical simulation of cirrus cloud radiative forcing using lidar backscatter data. Preliminary results, Óptica Pura y Aplicada, 41, 89-95, 2008.

Chen, T., Rossow, W. B., and Zhang, Y.: Radiative effects of cloudtype variations, J. Climate, 13, 264-286, 2000.
Dupont, J.-C. and Haeffelin, M.: Observed instantaneous cirrus radiative effect on surface-level shortwave and longwave irradiances, J. Geophys. Res., 113, D21202, doi:10.1029/2008JD009838, 2008.

$\mathrm{Fu}, \mathrm{Q}$.: An accurate parameterization of the solar radiative properties of cirrus clouds for climate models, J. Climate, 9, 20582082, 1996.

Freidenreich, S. M. and Ramaswamy, V.: A new multiple-band solar radiative parameterization for general circulation models, J. Geophys. Res., 104(D24), 31389-31409, 1999.

Futyan, J. M., Russell, J. E., and Harries, J. E.: Determining cloud forcing by cloud type from geostationary satellite data, Geophys. Res. Lett., 32, L08807, doi:10.1029/2004GL022275, 2005.

Haeffelin, M., Barthés, L., Bock, O., Boitel, C., Bony, S., Bouniol, D., Chepfer, H., Chiriaco, M., Cuesta, J., Delanoë, J., Drobinski, P., Dufresne, J.-L., Flamant, C., Grall, M., Hodzic, A., Hourdin, F., Lapouge, F., Lemaître, Y., Mathieu, A., Morille, Y., Naud, C., Noël, V., O'Hirok, W., Pelon, J., Pietras, C., Protat, A. Romand, B., Scialom, G., and Vautard, R.: SIRTA, a ground-based atmospheric observatory for cloud and aerosol research, Ann. Geophys., 23, 262-275, doi:10.5194/angeo-23-253-2005, 2005.

Jensen, E. J., Kinne, S., and Toon, O. B.: Tropical cirrus cloud radiative forcing: Sensitivity studies, Geophys. Res. Lett., 21, 2023-2026, 1994.

Khvorostyanov, V. I. and Sassen, K.: Microphysical processes in cirrus and their impact on radiation: A mesoscale modeling perspective, in Cirrus, edited by: Lynch, D., Sassen, K., Starr, D. O. C., and Stephens, G., Oxford University Press, 397-432, 2002.

Mace, G., Benson, S., and Kato S.: Cloud radiative forcing at the Atmospheric Radiation Measurement Program Climate Research Facility: 2. Vertical redistribution of radiant energy by clouds, J. Geophys. Res., 111, D11S91, doi:10.1029/2005JD005922, 2006.

Nazaryan, H., McCormick, M. P., and Menzel, W. P.: Global characterization of cirrus clouds using CALIPSO data, J. Geophys. Res., 113, D16211, doi:10.1029/2007JD009481, 2008.

Poetzsch-Heffter, C., Liu, Q., Ruprecht, E., and Simmer C.: Effect of cloud types on the Earth radiation budget calculated with the ISCCP C1 dataset: Methodology and initial results, J. Climate, 8, 829-843, 1995.

Ramaswamy, V. and Freidenreich, S. M.: Solar radiative line-byline determination of water vapor absorption and water cloud extinction in inhomogeneous atmospheres, J. Geophys. Res., 96, 9133-9157, 1991.

Ramaswamy, V. and Ramanathan, V.: Solar absorption by cirrus clouds and the maintenance of the tropical upper troposphere thermal structure, J. Atmos. Sci., 46, 2293-2310, 1989.

Sassen, K. and Cho, B. S.: Subvisual - Thin cirrus lidar dataset for satellite verification and climatological research, J. Appl. Meteorol., 31, 1275-1285, 1992.

Sassen, K., Wang, Z., and Liu, D.: Global distribution of cirrus clouds from CloudSat/Cloud-Aerosol Lidar and Infrared Pathfinder Satellite Observations (CALIPSO) measurements, J. Geophys. Res., 113, D00A12, doi:10.1029/2008JD009972, 2008.

Schlimme, I., Macke, A., and Reichardt, J.: The impact of ice crystal shapes, size distributions, and spatial structures of cirrus clouds on solar radiative fluxes, J. Atmos. Sci., 62, 2274-2283, 2005. 
Stubenrauch, C. J., Chedin, A., Rädel, G., Scott, N. A., and Serrar, S.: Cloud properties and their seasonal and diurnal variability from TOVS Path-B, J. Climate, 19, 5531-5553, 2006.
Stubenrauch, C. J., Rossow, W. B., Scott, N. A., and Chedin, A.: Clouds as seen by satellite sounders (3I) and imagers (ISCCP), Part III: Spatial heterogeneity and radiative effects, J. Climate, 12, 3419-3442, 1999. 